\title{
Utility of adjunctive macrolide therapy in treatment of children with asthma: a systematic review and meta-analysis
}

\author{
Anar Mikailov' \\ Ilona Kane ${ }^{2}$ \\ Stephen C Aronoff ${ }^{3}$ \\ Raemma Luck ${ }^{3, \dagger}$ \\ Michael T DelVecchio 3 \\ 'Beth Israel Deaconess Medical \\ Center, Boston, MA, ${ }^{2}$ St Christopher's \\ Hospital for Children, Philadelphia, \\ PA, ${ }^{3}$ Department of Pediatrics, Temple \\ University School of Medicine, \\ Philadelphia, PA, USA \\ †Raemma Luck is now deceased
}

This article was published in the following Dove Press journal:

Journal of Asthma and Allergy

15 January 2013

Number of times this article has been viewed
Background: The purpose of this study was to investigate macrolides as an adjunct to an asthma controller regimen in children with asthma.

Methods: Prospective clinical trials of macrolide therapy in children with asthma using outcome measures of change in forced expiratory volume in one second $\left(\mathrm{FEV}_{1}\right)$ and/or oral corticosteroid requirement were searched for in PubMed up to December 2009. The reference lists of studies were also included in the analysis, as well as those listed in published meta-analyses.

Results: The literature search yielded 116 studies, six of which were included in this metaanalysis. The change in $\mathrm{FEV}_{1}$ from baseline with adjunctive use of macrolide therapy in all children was not significant $(0.25 \%$ predicted; $95 \%$ confidence interval $[\mathrm{CI}]-0.37,0.86$ predicted, $P=0.43$ ); however, the change in $\mathrm{FEV}_{1}$ among children receiving daily oral corticosteroids was significant (3.89\% predicted; $95 \% \mathrm{CI}-0.01,7.79, P=0.05$ ). Addition of macrolide therapy to the treatment of children with oral corticosteroid-dependent asthma resulted in a statistically significant decrease in daily corticosteroid dosage $(-3.45 \mathrm{mg} /$ day; $95 \% \mathrm{CI}-5.79,-1.09 \mathrm{mg} /$ day, $P=0.004)$. This reduction in daily corticosteroid dosage was directly proportional to the duration of macrolide therapy $(-0.17 \mathrm{mg}$ methylprednisolone per week of macrolide therapy; 95\% CI $-0.33,-0.021, P=0.025)$.

Conclusion: Addition of macrolides to the treatment regimen of children with oral corticosteroid-dependent asthma improves $\mathrm{FEV}_{1}$ and decreases the daily dosage of corticosteroids required for control in these children. The degree of dose reduction is directly related to the duration of macrolide therapy. Additional large, randomized, placebo-controlled trials of adjunctive macrolide use in children with oral corticosteroid-dependent asthma are required to verify this observation.

Keywords: chronic asthma, macrolides, corticosteroid sparing

\section{Introduction}

Asthma is a respiratory disease characterized by airway inflammation, airway hyperresponsiveness, and resultant reversible airway obstruction. Approximately $12 \%$ of children are afflicted with the disease, and it is the most common cause of childhood hospitalizations. ${ }^{1}$ Asthma therapy revolves around managing respiratory symptoms, airway inflammation, and airway hyper-responsiveness. ${ }^{1}$ Commonly used agents include bronchodilators and inhaled corticosteroids. ${ }^{1}$ Patients with more severe asthma require daily oral steroid therapy and occasionally immunosuppressive agents.

When managing chronic asthma in children, any side effects of the treatment modality become important. Recently, long-acting beta-agonists have received a black-box warning for monotherapy. ${ }^{2}$ Furthermore, corticosteroids are notorious for a wide range
Correspondence: Michael DelVecchio Department of Pediatrics, Temple University School of Medicine, $3440 \mathrm{~N}$ Broad Street 2nd Floor, Kresge West, Philadelphia, PA 19140, USA

Tel + I 2157076605

Fax + I 2157076443

Email michael.delvecchio@tuhs.temple.edu 
of detrimental effects, such as growth retardation, decreased bone mineral density, skin thinning, cataracts, glucose intolerance, hypertension, central obesity, and suppression of the hypothalamic-pituitary-adrenal axis. ${ }^{2,3}$ The 2008 Childhood Asthma Management Program study of long-term oral corticosteroid use in children with asthma found a dose-dependent increase in risk of osteopenia and a decrease in bone mineral accrual. ${ }^{4}$ Significant improvement in chronic treatment of asthma in children is necessary to address the morbidity and mortality associated with current approaches.

Antibiotics, especially macrolides, have been extensively investigated as a potential treatment in asthma, chronic obstructive pulmonary disease, and cystic fibrosis. ${ }^{5,6}$ Although many clinicians prescribe antibiotics in the setting of chronic asthma and its exacerbations, current national guidelines discourage such use. ${ }^{7,8}$ Nevertheless, due to their anti-inflammatory and antibacterial effects, macrolides show great potential as an adjunct treatment for asthma. ${ }^{9}$ Since the late $1950 \mathrm{~s}$, macrolide therapy has been recognized to improve outcomes in children and adults with asthma. ${ }^{10-16}$ In 1970, Itkin and Menzel ${ }^{17}$ reported a steroid-sparing effect of macrolides. In agreement with Itkin and Menzel, in a randomized controlled trial designed to investigate the effects of macrolide therapy on childhood asthma, Kamada et $\mathrm{al}^{14}$ showed a statistically significant steroid-sparing effect and an improvement in forced expiratory volume in one second $\left(\mathrm{FEV}_{1}\right)$. In contrast, a Cochrane meta-analysis of macrolide use for chronic asthma in children and adults showed insufficient evidence to support or refute use of macrolides. ${ }^{18}$ The present systematic review and meta-analysis was undertaken to determine the effect of macrolide therapy on management of asthma in children.

\section{Materials and methods}

We adhered to the Preferred Reporting Items for Systematic Reviews and Meta-Analyses (PRISMA) criteria when performing this study. The MEDLINE and EBM (EvidenceBased Medicine) Reviews/Cochrane Central Register of Controlled Trials databases were searched using both the Ovid and PubMed search engines, covering the period from 1950 to 2009. Search terms included "macrolides", "asthma", and "children", with a focus on the subtopics "treatment" and "therapy". A review of the bibliographies of selected references was also performed.

\section{Study selection and data extraction}

Inclusion criteria were a clinical diagnosis of asthma, age 2-18 years, a macrolide antibiotic used as an adjunctive controller, oral corticosteroid use with dosage determined before and after initiation of macrolide therapy, and FEV as percent predicted measured before and after initiation of macrolide therapy. Studies were excluded if presented as a review article or meta-analysis or if patients with chronic respiratory conditions other than asthma, such as cystic fibrosis, were included. The studies recovered from the database searches were screened by title, abstract, and article type. The methods sections from those studies that survived the initial cull were blindly reviewed for compliance with our inclusion criteria by MD and RL.

\section{Statistical analysis}

Differences in mean $\mathrm{FEV}_{1}$ and daily oral dosage of corticosteroids before and after therapy were computed for each study and for all studies combined. Heterogeneity among studies was determined by Cochrane's Q statistic and by calculating the resulting $P$ value. A $P<0.05$ was suggestive of significant heterogeneity. $\mathrm{I}^{2}$ was calculated to determine the extent of heterogeneity across studies. In cases where heterogeneity was significant, the studies were combined using the random-effects model. The effect of duration of macrolide therapy on daily oral corticosteroid dosage was determined by meta-regression; a $P$ value $<0.05$ for the slope of the regression line was considered to be statistically significant. All analyses were performed with meta-analysis software (Comprehensive Meta-Analysis version 2.0, Biostat Inc, Englewood, NJ, http://www.meta-analysis.com).

\section{Results}

\section{Literature flow}

The Ovid, MEDLINE, and PubMed searches yielded 116 references for review. From the 116 titles and abstracts, 22 references were excluded. The full text of 94 references was then reviewed and another 79 references were excluded, resulting in a total of 15 studies that were then reviewed by blinded team members (MD and RL). Of the 15 references, six $^{11-16}$ were included in the final report (Figure 1, Table 1). Because only two ${ }^{11,14}$ of the six included studies used a placebo group, the present study considered the pre and posttreatment groups only to maintain homogeneity.

The total pediatric sample size of the combined studies was 69 . Five prospective studies ${ }^{11-15}$ were identified and included in the analysis of macrolide therapy and $\mathrm{FEV}_{1}$ change (Table 2, Figure 2). Four studies ${ }^{13-16}$ were included in the analysis of macrolide therapy and oral corticosteroid dose change (Table 3, Figure 3), three of which were included in the subgroup meta-regression analysis. ${ }^{13-15}$ 


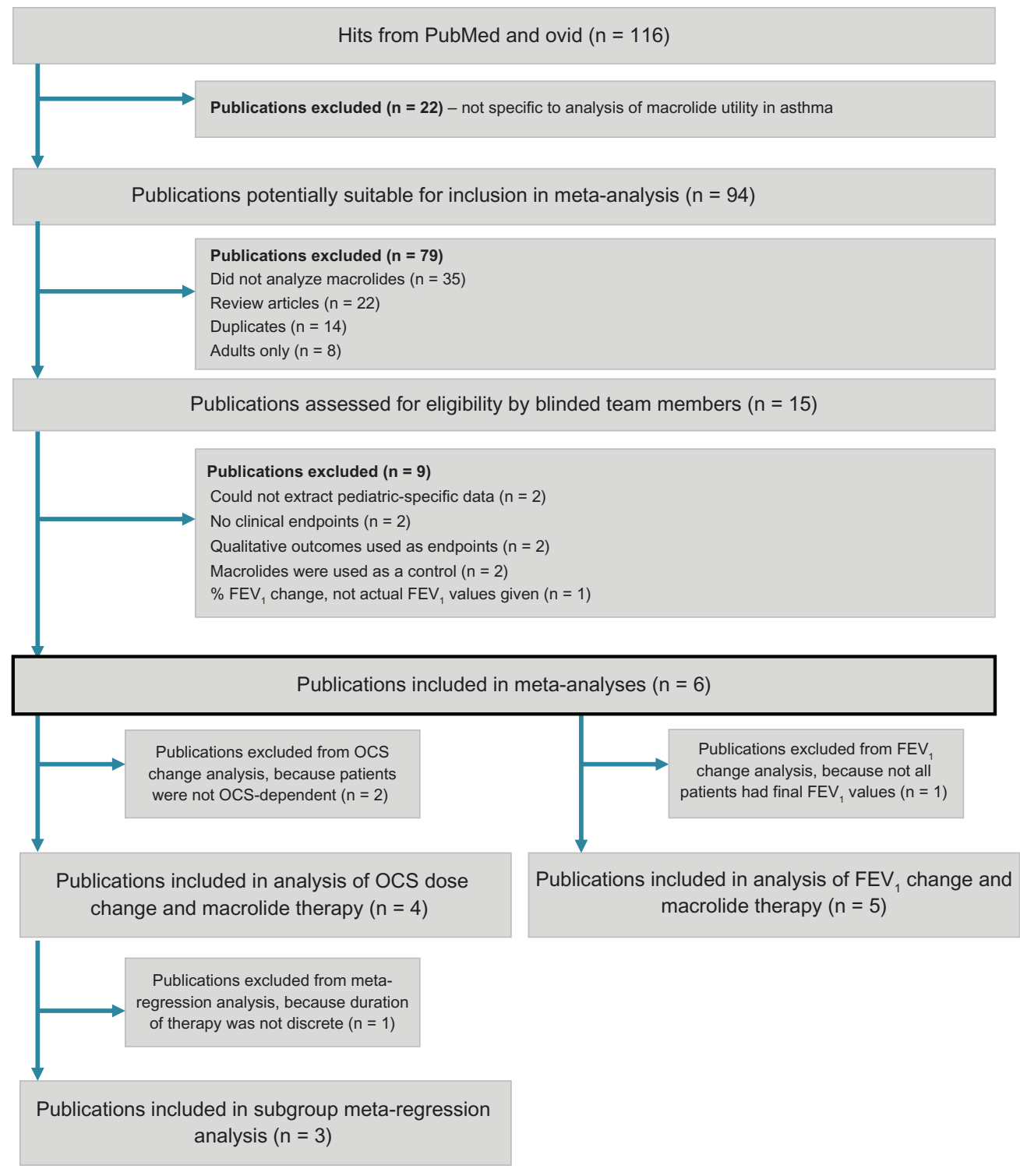

Figure I Flow chart of publications included in systematic review.

Abbreviations: $\mathrm{FEV}_{1}$, forced expiratory volume in one second; OCS, oral corticosteroids.

Table I Characteristics of studies included in meta-analysis of macrolide use in childhood asthma

\begin{tabular}{|c|c|c|c|c|c|c|c|}
\hline Study & $\mathbf{n}$ & $\begin{array}{l}\text { Age range, } \\
\text { years }\end{array}$ & $\begin{array}{l}\text { Outcome: FEV, change } \\
\text { or OCS dose change }\end{array}$ & Macrolide & Macrolide dosing & OCS & $\begin{array}{l}\text { Duration of macrolide } \\
\text { therapy, weeks }\end{array}$ \\
\hline $\begin{array}{l}\text { Piacentini et al" } \\
\text { (Italy) }\end{array}$ & 16 & 13.4 (mean) & FEV, only & Azithromycin & 10 mg/kg/day, 3 days $/$ week & None & 8 \\
\hline $\begin{array}{l}\text { Shimizu et a }{ }^{12} \\
\text { (Japan) }\end{array}$ & 12 & $11-15$ & FEV, only & Roxithromycin & 150 mg/day & None & 8 \\
\hline $\begin{array}{l}\text { Zeiger et al' } \\
\text { (US) }\end{array}$ & 3 & $13-16$ & $\mathrm{FEV}_{1}$ and $\mathrm{OCS}$ & TAO & $\begin{array}{l}\text { I g/day, tapered to } \\
250 \mathrm{mg} / \text { day }\end{array}$ & MPn & 6 \\
\hline $\begin{array}{l}\text { Kamada et al' }{ }^{14, \epsilon} \\
\text { (US) }\end{array}$ & 18 & $6-17$ & $\mathrm{FEV}_{\text {, }}$ and OCS & TAO & $\begin{array}{l}250 \mathrm{mg} / \text { day tapered to } \\
250 \mathrm{mg} \text { once daily }\end{array}$ & $M P n$ & 12 \\
\hline $\begin{array}{l}\text { Eitches et a }\left.\right|^{15} \\
\text { (US) }\end{array}$ & II & $7-13$ & $\mathrm{FEV}$, and OCS & TAO & $\begin{array}{l}\text { I g/day, tapered to } \\
250 \mathrm{mg} / \text { day }\end{array}$ & $M P n$ & 52 \\
\hline $\begin{array}{l}\text { Flotte et al }{ }^{16} \\
\text { (US) }\end{array}$ & 9 & $2-14$ & OCS only & TAO & $\begin{array}{l}250 \mathrm{mg} \text { twice daily, tapered } \\
\text { to } 250 \mathrm{mg} \text { once daily }\end{array}$ & MPn & $16-136$ \\
\hline
\end{tabular}

Note: ${ }^{€}$ The only study included in the Cochrane meta-analysis.

Abbreviations: MPn, methylprednisolone; TAO, troleandomycin; $\mathrm{FEV}_{1}$, forced expiratory volume in one second; OCS, oral corticosteroids. 
Table 2 Changes in FEV, with addition of macrolide

\begin{tabular}{|c|c|c|c|c|c|c|c|}
\hline Study & OCS use & Macrolide & $\mathbf{n}$ & $\begin{array}{l}\text { Duration of macrolide } \\
\text { treatment }\end{array}$ & $\begin{array}{l}\text { Pretreatment } \\
\text { FEV }, \pm \text { SEM }\end{array}$ & Post treatment FEV & $P$ \\
\hline Piacentini et al" & No & Azithromycin & $8^{\#}$ & 8 weeks & $73.5 \pm 12.9$ & $74.62 \pm 9.76$ & 0.84 \\
\hline Shimizu et $\mathrm{al}^{12}$ & No & Roxithromycin & 12 & 8 weeks & $81.5 \pm 2.2$ & $82.0 \pm 3.0$ & 0.64 \\
\hline Zeiger et $\mathrm{al}^{13}$ & Yes & TAO & 3 & 6 weeks & $67.3 \pm 12.4$ & $100 \pm 6.0$ & 0.01 \\
\hline Kamada et $\mathrm{al}^{14}$ & Yes & TAO & 6 & 12 weeks & $80.4 \pm 6.5$ & $73.6 \pm 6.3$ & 0.00 \\
\hline Eitches et $\mathrm{al}^{15}$ & Yes & TAO & 11 & 52 weeks & $54 \pm 4.8$ & $97 \pm 6.5$ & 0.08 \\
\hline
\end{tabular}

Notes: Excluded from this analysis because post treatment FEV, values were not recorded; \# only patients from the treatment group were used in our study to maintain homogeneity as described in the results section.

Abbreviations: TAO, troleandomycin; FEV , forced expiratory volume in one second; OCS, oral corticosteroids; SEM, standard error of the mean.

Of note, four of $\operatorname{six}^{11-14}$ studies specifically excluded patients with evidence of upper respiratory illness or viral infection. Piacentini et al reported that none of the patients in their study had clinical signs or symptoms or airway infections in the months before or during the study. ${ }^{11}$ Shimizu et al required that their subjects were free from upper respiratory tract infections for 4 weeks prior to study entry. ${ }^{12}$ Zieger et al noted that no patients had evidence of infection at the start of the study. ${ }^{13}$ Kamada et al excluded all patients who had evidence of respiratory infection within 4 weeks of enrollment. ${ }^{14}$ Eitches et $\mathrm{a}{ }^{15}$ and Flotte et $\mathrm{a}{ }^{16}$ did not specify viral illness as an exclusion criterion.

\section{FEV, change}

Table 2 presents the five studies included in the analysis of the effects of macrolide on $\mathrm{FEV}_{1}$ in children with asthma. Due to significant heterogeneity across studies
$\left(\mathrm{I}^{2}=89.80, \mathrm{Q}=39.23, P=0.002\right)$, the random-effects model was used. As seen in Figure 2, macrolide therapy had no impact overall on changes in $\mathrm{FEV}_{1}$. When subsets of studies were investigated, macrolide therapy failed to impact $\mathrm{FEV}_{1}$ in patients who were not oral corticosteroiddependent (standard difference in mean $=0.15 \%$ predicted; $95 \% \mathrm{CI}-0.47,0.77, P=0.63$ ), but had a significant impact on oral corticosteroid-dependent patients (standard difference in mean $=3.89 \%$ predicted; $95 \% \mathrm{CI}-0.01,7.79, P=0.05)$.

\section{Change in oral corticosteroid dose}

Table 3 and Figure 3 present the four studies included in the analysis of the effects of macrolide on oral corticosteroid dosing in children with asthma. The random-effects model was used due to significant heterogeneity across studies $\left(\mathrm{I}^{2}=82.49, \mathrm{Q}=17.14, P<0.05\right)$. Addition of macrolide therapy in children with oral corticosteroid-dependent

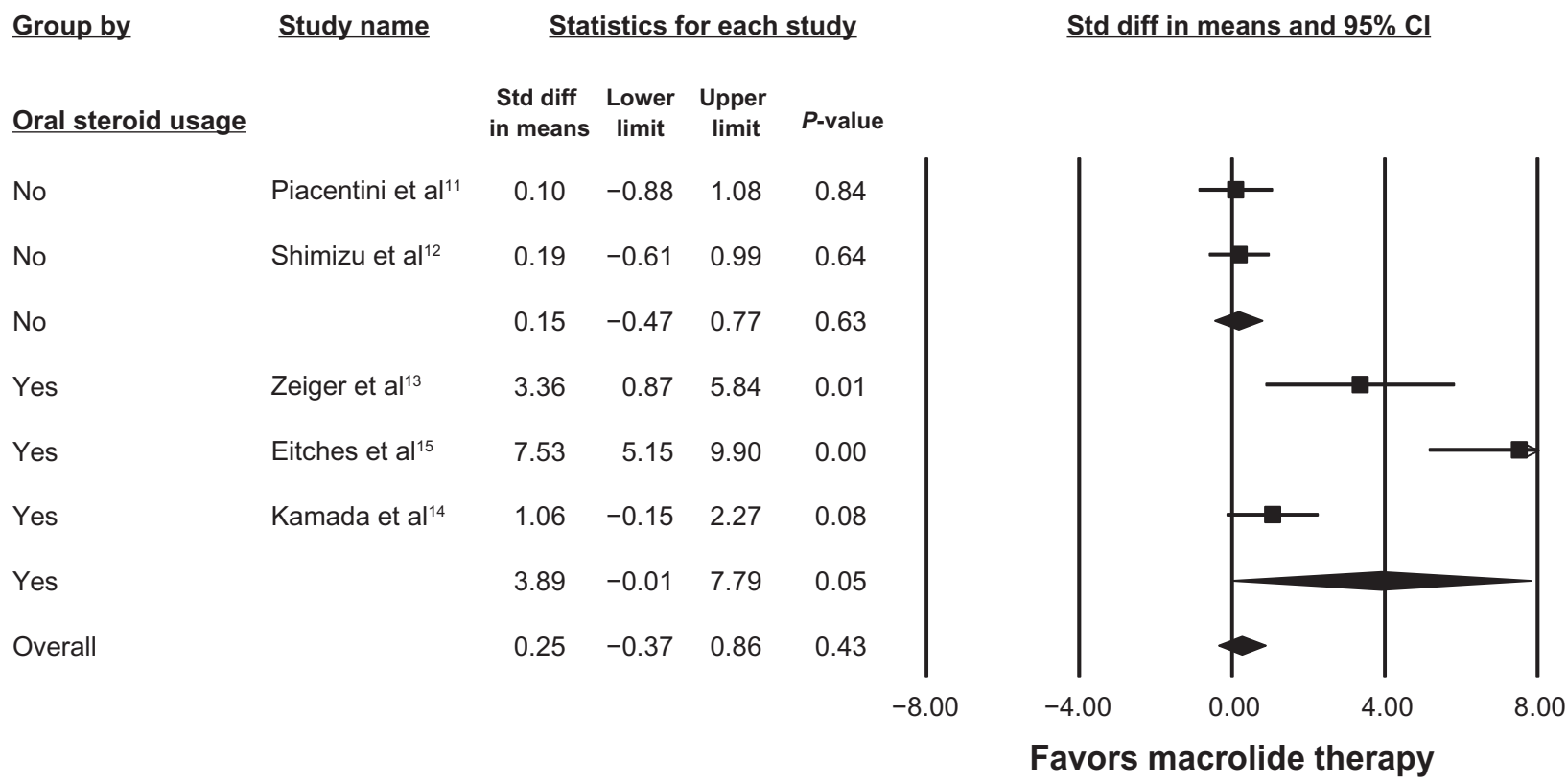

Figure 2 Random effects model analysis of adjunctive macrolide use and FEV, change in children with asthma.

Notes: Grouping by oral corticosteroid use. $I^{2}=89.80, Q=39.23, P<0.002$.

Abbreviations: $\mathrm{Cl}$, confidence interval; $\mathrm{FEV}_{1}$, forced expiratory volume in one second. 
Table 3 Changes in OCS dose with addition of macrolide

\begin{tabular}{|c|c|c|c|c|c|c|c|}
\hline Study & Macrolide & OCS & $\mathbf{n}$ & $\begin{array}{l}\text { Duration of macrolide } \\
\text { treatment (weeks) }\end{array}$ & $\begin{array}{l}\text { Pretreatment OCS } \\
\text { dose } \pm \text { SEM (mg/day) }\end{array}$ & $\begin{array}{l}\text { Post treatment OCS } \\
\text { dose } \pm \text { SEM (mg/day) }\end{array}$ & $P$ \\
\hline Zeiger et $\mathrm{al}^{13}$ & TAO & $M P n$ & 3 & 6 & $19.3 \pm 6.8$ & $14.7 \pm 4.7$ & 0.002 \\
\hline Kamada et $\mathrm{al}^{14}$ & TAO & $M P n$ & $6^{\#}$ & 12 & $34.2 \pm 9.6$ & $4.9 \pm 1.0$ & 0.00 \\
\hline Eitches et $\mathrm{al}^{15}$ & TAO & $\mathrm{MPn}$ & $10^{t}$ & 52 & $19.8 \pm 3.1$ & $3.2 \pm 0.4$ & 0.00 \\
\hline Flotte et $\mathrm{a}^{16}$ & TAO & $M P n$ & 9 & $16-136^{\Omega}$ & $15.3 \pm 3.04$ & $1.4 \pm 0.26$ & 0.245 \\
\hline
\end{tabular}

Notes: Piacentini et al and Shimizu et al are excluded because their patients were not OCS-dependent. ${ }^{\mathrm{A}}$ Although there were II patients in the study, one patient's baseline methylprednisolone dose was described as "variable" and not included in this analysis; ${ }^{\Omega}$ duration of therapy was not specified per patient; \# only the patients from the TAO$\mathrm{MPn}$ group were used in our study to maintain homogeneity as described in the results section. ${ }^{13-15}$ The studies included in the meta-regression analysis. Flotte et al was excluded because duration was not discretely defined for each patient.

Abbreviations: TAO, troleandomycin; OCS, oral corticosteroids; MPn, methylprednisolone; SEM, standard error of the mean.

asthma resulted in a statistically significant decrease in daily corticosteroid dosage $(-3.45 \mathrm{mg} /$ day; $95 \% \mathrm{CI}-5.79,-1.09$, $P=0.004)$. The effect of duration of macrolide therapy on daily oral corticosteroid dosage was determined by metaregression. As the duration of macrolide therapy increased, the daily oral corticosteroid dosage was reduced by $0.17 \mathrm{mg}$ per week $(95 \% \mathrm{CI}=0.021-0.33 \mathrm{mg}$ of Methylprednisolone per week of macrolide therapy, $P=0.025$ ).

\section{Discussion}

The present study found that while adjunctive macrolide therapy did not affect $\mathrm{FEV}_{1}$ in children without oral corticosteroid-dependent asthma, $\mathrm{FEV}_{1}$ improved in children with oral corticosteroid-dependent asthma. Moreover, among children requiring daily oral corticosteroids for control of asthma, addition of a macrolide agent decreased daily oral corticosteroid dosage requirements, and the degree of this reduction was directly proportional to duration of macrolide therapy.

While the utility of macrolide therapy in asthma has been well studied in the general population, it has been poorly studied in childhood asthma. Richeldi et $\mathrm{al}^{18}$ reviewed randomized controlled trials of macrolide administration in patients with asthma, and identified a sample size of 398 adults from six studies, and 18 children from one study. This meta-analysis found insufficient evidence to recommend macrolide therapy in patients with chronic asthma. In particular, the authors failed to find that macrolide therapy had a significant impact on daily oral corticosteroid dosage. This last conclusion was based on two studies. Nelson et a ${ }^{19}$ studied 75 adults and did not find a difference in daily oral corticosteroid dosage between their treatment and placebo groups. Kamada et $\mathrm{al}^{14}$ studied 11 children, and found a statistically significant reduction in daily oral corticosteroid dosage for children receiving macrolide therapy when compared with a placebo group. The present study, which found an effect of macrolide therapy on daily oral corticosteroid dosage, included parallel and crossover clinical trials involving only children. These observations suggest that macrolide therapy may have a steroid-sparing effect in children but not in adults. Further studies are needed to resolve this issue.

Potential mechanisms of macrolide effects are likely related to modulation of inflammatory cytokines, such as interleukin (IL)-5, IL-8, and vascular endothelial growth factor (VEGF). In a prospective cohort study from 2010, Korematsu et $\mathrm{al}^{20}$ showed a correlation between children with severe asthma and high levels of IL-8 and VEGF. Furthermore, that study showed that low-dose erythromycin

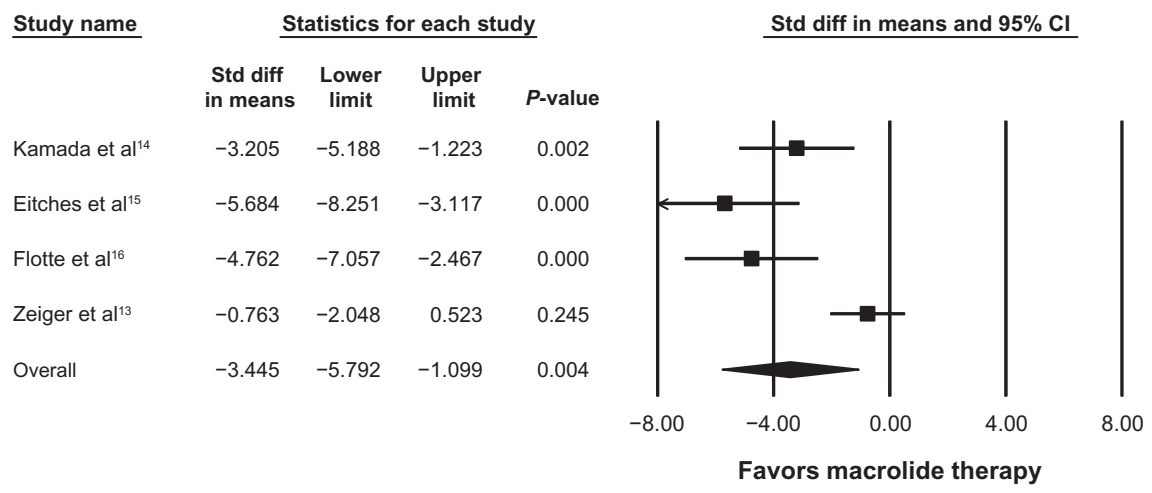

Figure 3 Random effects model analysis of adjunctive macrolide use and oral steroid dose change in children with asthma. Notes: $I^{2}=82.49, Q=17.14, P<0.05$. 
significantly improved clinical symptoms and decreased levels of both IL8 and VEGF in children with severe asthma, but not in children with mild to moderate asthma. ${ }^{20}$ In a cross-sectional controlled study performed in 2011, Lin et $\mathrm{al}^{21}$ showed that children with asthma produced significantly higher levels of IL-5 compared with children without asthma, and addition of azithromycin significantly decreased IL-5 levels in a dose-dependent fashion. In the present study, the most severely affected children, ie, those who were dependent on oral corticosteroids, saw the most benefit from macrolide therapy, a result that is likely related to the pathophysiology observed in the Korematsu et al ${ }^{20}$ study. It is unclear why children but not adults (as determined by a Cochrane review ${ }^{18}$ ) show significant steroid-sparing effects from adjunctive macrolide therapy. The common saying may be appropriate here, ie, that "children are not simply young adults".

The present study has several limitations. First, troleandomycin and methylprednisolone were used in all studies where a steroid-sparing effect was observed. Prior studies have suggested a pharmacokinetic interaction between these two agents that directly increases steroid concentrations. ${ }^{13,22}$ It is not known whether this same effect exists between other members of the macrolide and corticosteroid classes. Another significant limitation is sample size: our aggregate data analyzed a total of 69 patients from six studies, and four of these $(n=28)$ were analyzed for steroid-sparing effect. Nevertheless, to the authors' knowledge, this is the largest sample size to date to have evaluated the effect of macrolides in children with corticosteroid-dependent asthma. Further, the studies were performed many years earlier, in some cases 30 years ago, when definitions and standard of care protocols were different from those used today. Furthermore, although the improvement in $\mathrm{FEV}_{1}$ was statistically significant, it may not necessarily be clinically significant, and future studies should include outcomes, such as responses to an asthma symptom questionnaire and numbers of acute care visits.

In summary, this study demonstrates that macrolides have a steroid-sparing effect in children with steroid-dependent asthma. In addition, we found a direct association between duration of macrolide therapy and magnitude of change in oral corticosteroid dosage before and after therapy. The present study supports the need for a large, randomized, placebo-controlled, crossover trial of a modern macrolide in children with steroid-dependent asthma.

\section{Disclosure}

The authors report no conflicts of interest in this work.

\section{References}

1. Behrman RE, Kliegman RM, Jenson HB, editors. Nelson Textbook of Pediatrics. 17th ed. Philadelphia, PA: Saunders Elsevier Science; 2004.

2. Kramer JM. Balancing the benefits and risks of inhaled long-acting beta-agonists - the influence of values. N Engl J Med. 2009;360: 1592-1595.

3. Peters SP. Safety of inhaled corticosteroids in the treatment of persistent asthma. J Natl Med Assoc. 2006;98:851-861.

4. Kelly HW, Van Natta ML, Covar RA, Tonsacia J, Green RP, Strunk RC. Effect of long-term corticosteroid use on bone mineral density in children: a prospective longitudinal assessment in the Childhood Asthma Management Program (CAMP) study. Pediatrics. 2008;122:e53-e61.

5. Rubin BK, Henke MO. Immunomodulatory activity and effectiveness of macrolides in chronic airway disease. Chest. 2004;125:70S-78S.

6. Equi A, Balfour-Lynn IM, Bush A, Rosenthal M. Long term azithromycin in children with cystic fibrosis: a randomised, placebocontrolled crossover trial. Lancet. 2002;360:978-984.

7. Paul IM, Maselli JH, Hersh AL, Boushey HA, Nielson DW, Cabana MD. Antibiotic prescribing during pediatric ambulatory care visits for asthma. Pediatrics. 2011;127:1014-1021.

8. De Boeck K, Vermeulen F, Meyts I, Hutsebaut L, Frackaert D, Proesmans M. Coprescription of antibiotics and asthma drugs in children. Pediatrics. 2011;127:1022-1026.

9. Shinkai M, Rubin BK. Macrolides and airway inflammation in children. Paediatr Respir Rev. 2005;6:227-235.

10. Kaplan MA, Goldin M. The use of triacetyl-oleandomycin in chronic infectious asthma. Antibiot Annu. 1959;6:273-276.

11. Piacentini GL, Peroni DG, Bodini A, et al. Azithromycin reduces bronchial hyperresponsiveness and neutrophilic airway inflammation in asthmatic children: a preliminary report. Allergy Asthma Proc. 2007;28:194-198.

12. Shimizu T, Kato M, Mochizuki H, Tokuyama K, Morikawa A, Kuroume T. Roxithromycin reduces the degree of bronchial hyperresponsiveness in children with asthma. Chest. 1994;106:458-461.

13. Zeiger RS, Schartz M, Sperling W, Simon RA, Stevenson DD. Efficacy of troleandomycin in outpatients with severe corticosteroid dependent asthma. J Allergy Clin Immunol. 1980;66:438-446.

14. Kamada AK, Hill MR, Ikle DN, Brenner AM, Szefler SJ. Efficacy and safety of low-dose troleandomycin therapy in children with severe, steroid-requiring asthma. J Allergy Clin Immunol. 1993;91:873-882.

15. Eitches RW, Rachelefsky GS, Katz RM, Mendoza GR, Siegel SC. Methylprednisolone and troleandomycin in treatment of steroid dependent asthmatic children. Am J Dis Child. 1985;139:264-269.

16. Flotte TR, Loughlin GM. Benefits and complications of troleandomycin (TAO) in young children with steroid-dependent asthma. Pediatr Pulmonol. 1991;10:178-182.

17. Itkin IH, Menzel ML. The use of macrolide antibiotic substances in the treatment of asthma. J Allergy. 1970;45:146-162.

18. Richeldi L, Ferrara G, Fabbri L, Lasserson TJ, Gibson PG. Macrolides for chronic asthma. Cochrane Database Syst Rev. 2005;4:CD002997.

19. Nelson HS, Hamilos DL, Corsello PR, Levesque NV, Buchmeier AD, Bucker BL. A double-blind study of troleandomycin and methylprednisolone in asthmatic subjects who require daily corticosteroids. $\mathrm{Am}$ Rev Respir Dis. 1993;147:398-404.

20. Korematsu S, Yamamoto K, Tomokazu N, et al. The indication and effectiveness of low-dose erythromycin therapy in pediatric patients with bronchial asthma. Pediatr Allergy Immunol. 2010;21:489-492.

21. Lin SJ, Lee WJ, Liang YW, Yan DC, Cheng PJ, Kuo ML. Azithromycin inhibits IL-5 production of T helper type 2 cells from asthmatic children. Int Arch Allergy Immunol. 2011;56:179-186.

22. Spector SL, Katz FH, Farr RS. Troleandomycin effectiveness in steroid-dependent asthma and bronchitis. J Allergy Clin Immunol. $1974 ; 54: 367$. 
Journal of Asthma and Allergy

\section{Publish your work in this journal}

The Journal of Asthma and Allergy is an international, peer-reviewed open-access journal publishing original research, reports, editorials and commentaries on the following topics: Asthma; Pulmonary physiology; Asthma related clinical health; Clinical immunology and the immunological basis of disease; Pharmacological interventions and

new therapies. Issues of patient safety and quality of care will also be considered. The manuscript management system is completely online and includes a very quick and fair peer-review system, which is all easy to use. Visit http://www.dovepress.com/testimonials.php to read real quotes from published authors.

Submit your manuscript here: http://www.dovepress.com/journal-of-asthma-and-allergy-journal 